\title{
Research and CAD Application of the Lifting Mechanical Model based on the Mast Structure
}

\author{
Ying Zhao \\ Nanchang Key Laboratory of Material and Structure Detection, Jiangxi University of Technology
}

Keywords: Mechanical Model; Lattice Mast Assembly Design System; Visual Basic 6.0 ; Access Database

\begin{abstract}
Mast crane integral installation technology is one of the ten new technologies in the construction field, which are put forward by the ministry of construction and are in key application. It is widely applied in the field of construction engineering. However, at present, the design of the mast crane hoisting is generally based on traditional mechanical model and adopts manual calculation, which is lack of safety and reliability, and the model needs to be perfect. As a result, this paper studies the lattice mast crane hoisting system, explores and improves the traditional mechanical model, and develops the lattice mast hoisting aided design system (WGCAD1.0), in order to meet the design requirements. Main content includes: introduction to the development in engineering of the lattice mast hoisting crane and the application status in hoisting engineering of computer technology; introduction of the development environment of ViusalBasi6.0 and Access database which are used in cad system development of the lattice mast hoisting. By using the reasonable lattice mast lifting design mechanics model, from the lattice mast hoisting system designer's perspective, the software adopts Visual Basic 6.0 development environment and Microsoft Access database as development tools, the design idea of engineering design are simulated.
\end{abstract}

\section{Introduction}

In the large sports venues, large towers, jar, container loading, as well as the bridge construction process of China, the mast crane equipment hoisting is still used in lifting and placing. In the process of design and construction, the individual company compiles a computer program which analyzes the mechanical characteristics of mast structure, and studies the feasibility of the scheme by simulating the site conditions of the field.

Because the lattice mast structure is statically indeterminate spatial structure system, under the load, the stress of the structure is very complex. Mast shaft stiffness is a fairly continuous elastomer, and the top of the line wind rope links to the spring wind plate of the mast while the bottom links to the diagonal cable structure on the ground. In the process of hoisting, the cable wind rope node is in horizontal direction with nonlinear force and displacement. At this moment, the cable wind rope has the effect of nonlinear elastic support to the mast shaft. In practical engineering use, the simplified mechanical model is commonly used, which can to a certain extent reduce the calculation workload with poor calculation accuracy and poor reliability. The problems of this mechanical model are as follows:

Mast crane is a hoisting tool very widely used in building engineering construction. Because it has a big weight, simple production, convenient installation, low construction cost, etc, it can be used for 
a variety of special occasions, such as the integral hoisting place of towers, tanks, containers, chimney and other large equipment in petrochemical, metallurgy, electric power ind ustries. It can be qualified for the impossible task for general hoisting machinery hoisting.

Given the importance of the mast crane in the construction industry, in the 10 key new technologies promoting the construction proposed in 1994 by the ministry of construction, mast crane installation technology was in it. Under specific condition, the installation technology cannot only complete the weight lifting task, but also obtain ideal economic effect. The file put forward goals and measures, namely "in undertaking large components or equipment installation engineering or comparing the various lifting scheme and technical conditions, the enterprise shall consider the traditional hoisting process of China according to the engineering characteristics, use simple lifting equipment to conduct overall ascension to complete big installation task. Under certain conditions, the technology can achieve the effect which is technically feasible and economically rational. In practice, modern advanced technology shall be gradually improved to make it more perfect with more new ideas."

In this paper, the lattice crane is considered as a system engineering, from the perspective of system engineering, improve the mechanical principle of the traditional lattice mast crane, optimize the design of the lattice mast cranes; and on the basis of the improvement and optimization, by using modern computer technology as a tool and ViusalBasci6.0 and Access database software tools, develop lattice mast hoisting auxiliary software design, make the traditional mast cra ne be combined with computer technology, which is advantageous for the mast crane installation technology to be promoted in the construction industry.

\section{Content}

Development of mast aided design system (WGCAD1.0) tools. Due to that the user object of the mast hoisting aided design system is regular site construction technical personnel, considering the applicability and audience of the software, Visual Basic 6.0 is used as the development tool and Microsoft Access is used as the database in the mast hoisting aided design system.

Visual Basic 6.0 (VB6 for short), launched in 1998 by Microsoft, is a component of Visual Studio 98. VB6 is an integrated development environment (IDE), which is a combination of editing, test, program debugging and all kinds of application development tools. It is a kind of visualization, object-oriented development language of Windows. From the beginning of its launch, VB6 is easy to use, commonly used and of high efficiency. In the top development place, it is the main language of key tasks. It can do anything you want it to do. As Bill Gates said, "the world's most Windows applications are written by VB."

Compared with the VC, DEPLHI and other platforms, the biggest advantage of VB is easy to learn and the development time is short and the development efficiency is high. VB syntax is simple, the degree of visualization high. VB has fewer concepts. It is very suitable for Windows programming. However, the disad vantages are low speed after compiling, which has a great need of operation time base to support; the difficult software releases (if the compiled EXE program does not run on the computer installed with $\mathrm{VB}$, the file with $\mathrm{M}$ copied is needed and other setting works are needed); less low-level calls means, which is not suitable for the situation when the development hardware operation is much and the requiring speed is high. For example, writing hardware drivers will not be able to use VB. 
Database is a "set" used to achieve certain purposes and made according to certain rules. It is managed by software called database management system. The access mode of the database is independent of the application that uses it. The main characteristics of the database: data sharing, data with minimum redundancy, data integrity, data security, data independence. The data in the database can be used by the operation functions provided by the data management system (DBMS) or by the application. Application is a compiled series of ordered set of commands, in order to solve a specific management or data processing task. According to the above analysis, considering the characteristics of data processing in the mast hoisting aided design system, this paper uses the relational data model; based on the data model method adopted, this paper uses the relational database. At the same time, it uses Access as data management system (DBMS).

The model and program imple mentation of mast aided design system. WGCAD 1.0 system needs a data to store large amounts of standardized data. The data concludes and summarizes the experience data, which is not standard in the real construction, and makes it standardization and to be convenient programming needs. This WGCAD 1.0 system adopts Microsoft Access 2002 data management system. The database storage file is d.bmdb, which is saved in the same content with application documents. The database system contains "lattice mast one foot specification table", "wire rope specifications and load performance table" series, "mast angle type table", "steel structure stability coefficient table", "hoist type table", "reference design knuckle ball base table", "wind mast cable tray design reference table", "wind load shape coefficient table", "wind pressure height coefficient table", "pulse effect coefficient table", "pulse increase coefficient table", "the wind vibration coefficient table", etc. There are 18 tables in total. With independence between each data table, there is no relationship between each other. The maintenance of the database can be artificial, in order to ensure that the update of design parameters.

"Mast angle type table", "cross section steel structure stability coefficient table" and "calculated length coefficient table" are needed in the main structure form design of the mast, in which there is a corresponding relationship between "mast angle type table" and "single foot lattice masts specification selection table". The three forms are needed in the design of the main mast limb and the oblique article composes. In WGCAD1.0 system, users do not need to directly read about the three forms. By means of embedded, procedures obtain design information in the form automatically.

WGCAD 1.0 system consists of two main modules: the main structure design and the pertaining structure design. The main design module includes the mast section design, analysis and calculation of the axial force, analysis and calculation of the bending moment, mast section checking. The relationship of the modules of the main structure design is shown in Fig. 3.6. The pertaining structure design includes wire rope and mast top design, lug design, jacking and cable wind plate design, foundation base and anchor block. The relationship of the modules of the pertaining structure design is shown in Fig. 1. 


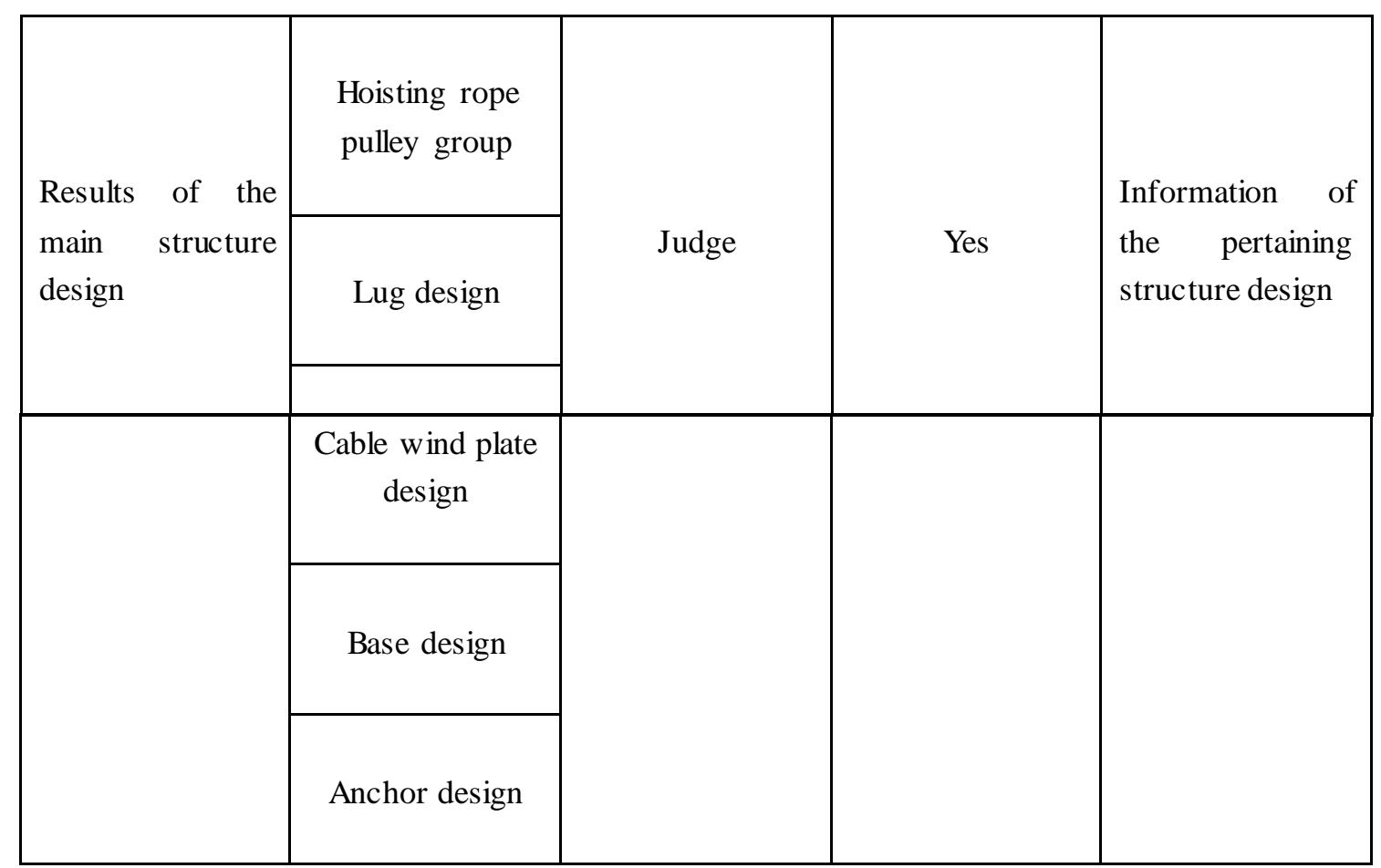

Fig. 1 The relationship of the modules of the pertaining structure design

Through simple derivation, the axial pressure of the hoisting load acting on the mast can be calculated approximately as follows:

$$
\mathrm{N}_{1}=\frac{\mathrm{K}_{1} \times \mathrm{K}_{2} \times(\mathrm{P}+\mathrm{Q}) \times(\mathrm{a}+\mathrm{c}) \times l}{a \times H}
$$

In the formula:

$K_{1}$-dynamic load coefficient;

$K_{2}$ - uneven coefficient;

$\mathrm{P}$ - lifting weight (unit: tons);

Q 一 weight of the lifting tackle (unit: tons);

$\mathrm{C}$ - the horizontal distance from the bottom of the mast to anchor bar (unit: $\mathrm{m}$ );

$\mathrm{c}$ - lifting radius (unit: $\mathrm{m}$ );

The height of the top of the mast to the ground (unit :); after simple derivation, the join forces in the plane produced by line wind rope in the spring wind plate can be calculated approximately as follows:

$$
\mathrm{T}_{\text {合 }}=\frac{\mathrm{K}_{1} \times K_{2} \times(P+Q)}{a \times \sin \alpha}
$$

In the formula:

The angle of the cable wind rope and the ground;

The axis force of $\mathrm{T}$ produced along the axis of the mast can be calculated approximately as follows:

$$
N_{2}=T_{\text {合 }} \times \sin (\alpha+\beta)
$$

The selection of wire rope and hoist. After completing the main design requirements of the mast, WGCAD 1.0 system is into the pertaining structure design, including selection of wire rope and hoist, lug design, jacking and cable tray design, wind mast foundation base design and anchor design. In view of the design conditions provided by main module design, the pertaining design the main module adopts different selection and design of machinery, equipment and affiliates, which is convenient for the engineering design needs. On the interface, there are three Frame containers, 
which are respectively complete three designs of the section of hoisting wire rope, cable wind rope and hoist. The calculation of steel wire rope tension

Through a guide pulley, hoisting rope is into the hoist drum, and the tension of the wire rope is as follows:

$$
S=N_{2} \times \mathrm{f}^{m}
$$

In the formula:

$\mathrm{f}$ - The rotational resistance coefficient of a single pulley:

$\mathrm{m}$-The number of guide pulley blocks;

$N_{2}$ - The force of the rounded rope of the hoisting tackle on the mast (unit: KN);

Wire rope choice model

The pulling force which the wire rope can afford can be calculated as follows:

$$
P=\frac{K \times S}{a}
$$

In the formula:

$\mathrm{K}$ - Wire rope safety factor;

a--- Considering non-uniform coefficients of the load of wire rope;

According to the calculated pulling force $\mathrm{P}$ of the wire rope, query "wire rope specifications table" in the database, select suitable wire rope, to allow the breaking force $\mathrm{P}[\mathrm{g}]>\mathrm{P}$. Normally, the wire rope with the specification of $6 \times 37$ should be chosen.

In the engineering design, general cable wind rope is with the specification of $6 \times 19$. The diameter of the wire rope is generally decided by the calculation load of the steel wire. There are mainly three measures to calculate the load:

Directly use the maximum tension of the main cable wind rope when cable wind rope is loading bearing. The characteristics of this method is that if there is only one cable wind rope hoisting system be in force, it can be calculated when simplifying the hoisting system as a planar force system; when there are many main cable wind ropes, the method is not very economic.

Take the maximum tension as the computational load of cable wind rope without considering the initial tension of the cable wind rope. The method thinks that the initial tension of the cable wind rope is not big. When the mast is in stress, the auxiliary cable wind rope is basically in a state of relaxation. As a result, the static equilibrium of the loading mast has nothing to do with the initial tension of the cable wind rope.

The design of the cable wind rope pulling force includes the designs of the main cable wind rope and the deputy cable wind rope. In construction, distribution coefficient method is usually used, which is to simplify the mast hoisting system of $3 \mathrm{~d}$ mechanical model into the plane stress model, to get the whole pulling force of the cable wind rope in the plane, and then to select different distribution coefficients according to the decoration forms of the cable wind rope, as follows:

$$
T_{\text {主 }}=\mathrm{K}_{\text {主 }} \times \mathrm{T}_{\text {合 }}
$$

In the formula:

$\mathrm{K}_{\text {主 }}$-Main cable wind rope distribution coefficient; 
Calculate the pulling force of the main cable wind rope and the deputy cable wind rope. The pulling force of the main cable wind rope can be calculated as follows:

$$
T_{\text {副 }}=\mathrm{K}_{\text {副 }} \times \mathrm{T}_{\text {合 }}
$$

In the formula:

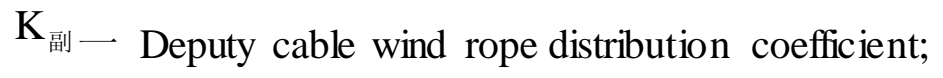

\section{Conclusions}

This paper systematically analyzes the mechanical principle of lattice mast cranes, puts forward the improvement measures for some of the original theory, and discusses the ideas and methods of the development of the mast hoisting tools design system (WGCADI. 0) in details. Through the one year deep study on the subject, the author basically achieves the following results:

Improve the calculation method of initial tension cable wind rope, and consider the effect of the geometric nonlinearity of cable wind rope and the influence of wind vibration of cable wind rope. The parabolic model is used to approximately instead. Improve the method which only considers the influences of static wind in the traditional mast wind load design method, put forward in the wind vibration design, the influence of the dynamic characteristics of the mast structure must be considered. Use an equivalent static amplification wind vibration coefficient, conduct linear amplification to static wind load. Considering the influence of the second order moment effect to lattice mast structure, get the displacement of the top mast deviator and put forward in the process of actual construction, the lattice mast structure should shift to the opposite direction, to reduce the influence of the second order effect. From the perspective of application parametric design, the design of the non-standard equipment in the lattice mast structure design, such as wind cable tray, mast base, winch, etc, are standardized. Database is established which is convenient for the further programming.

Using VB. 60 and Access, compile the lattice mast hoisting aided design system (WGCAD 1.0), computerize the lattice mast hoisting systems engineering. The system provides the mast design with a lifting weight below 100 tons and a lifting height below 60 meters. The system uses a graphical input interface, according to the prompt, inputs the related size of each data in the graphical windows, clicks "design", the software can calculate the real-time data of the design module and deposit into Word document.

This research work mainly focuses on the program implementation of the mechanics principle of the lattice mast structure when hoisting without including the specific engineering problems. The software need to be further perfected, which mainly include the following aspects:

WGCAD 1.0 software also needs to be further optimized and improved. Because, this software has not been used in the engineering practice and has not got the actual project examination, it may have some functions which are not perfect or not applicable. These problems need to be tested in engineering practice.

WGCAD 1.0 software is mainly in accordance with the lattice mast structure lifting, which is widely used in engineering. Follow-up work to the rest of the assembly method of mast structure, including sliding, down, seizing, hanging, swinging, more mast lift hanging, pushing, changing cable, rotation and so on, can be carried by the programming. Make the software as the structure type mast hoisting design expert system. 
WGCAD 1.0 software is mainly from the angle of the mast lifting force principle to design, without considering the influence of the specific construction environment. It needs to further study the influence of the external environment on the lifting design and how to take measures.

\section{Acknowledgment}

This work was supported by Project on professional and characteristical construction of Jiangxi province 2010 (Civil Engineering) and Project on the planning and construction of disciplines in Jiangxi University of Technology (Structure Engineering)

\section{References}

[1] Bo H. CAD Investigation into control structure of electrohydraulic proportional position synchronized control system [J][J]. MACHINE TOOL \& HYDRAULICS, 1997, 1: 002.

[2] Wang Qingguo 1, Jia Chunqiang 1, Zhang Eniun 2 (1 School of Mechanical Engineering, Shenyang University of Technology, Shenyang 110023 China); Improvement of 2MN Import Hydraulic Folding Machine[J]; Machine Tool \& Hydraulics;2003-03

[3] HU Wanqiang, WU Zhangyong, LUO Jing, YUAN Zirong,SONG Liguo (Faculty of Mechanical and Electrical Engineering, Kunming University of Science and Technology, Kunming 650093,China); Application of Electro-hydraulic Proportional Control Technology in the Stacking Equipment of Electrolytic Lead[J]; Machine Tool \& Hydraulics; 2006-01

[4] PU Danli,LIU Li (School of Mechanical Eng., Shanghai Jiaotong Univ., Shanghai 200240,China); Synchronous System of High Accuracy Position of the Internal High-pressure Forming Equipment Based on SIT[J]; Machine Tool \& Hydraulics;2008-06

[5] ZHOU An,TIAN Yong, ZHOU Quan-Shen,DONG Bin College of Electro-Mechanical Engineering, Henan University of Technology, Zhengzhou Henan 450052, China); Hydraulic Synchronization System about Two Lifting Point Gate[J]; Development \& Innovation of Machinery \& Electrical Products;2006-04

[6] Huang Haodong, Chen Zongji (Beijing University of Aeronautics and Astronautics, Dept. of Automatic Control); Virtual Prototyping and Virtual Prototype in Control System[J]; JOURNAL OF BEIJING UNIVERSITY OF AERONAUTICS AND ASTRONAUTICS; 1999-03

[7] Yong Qing(Mechanical Engineering College, USTB, Beijing 100083, PRC); Dynamic Characters of Load Sensing Pamp Control System[J]; JOURNAL OF UNIVERSITY OF SCIENCE AND TECHNOLOGY BEIJING;1996-02

[8] Gao Jianchen; Li Weijun; Chen Zhilong; Wu Pingdong (Mechatronics Training Center, Beijing Institute of Technology, Beijing 100081); Hydraulic Cylinder Servo Position Control Using a Fuzzy Controller[J]; JOURNAL OF BEIJING INSTITUTE OF TECHNOLOGY;1995-04

[9] Gao Jianchen; Chen Zhilong;Wu Pingdong (Mechatronics Center, Beijing of Technology, Beijing 100081); Neural-Network Based Fuzzy Controller Applying a Digital Signal Processor[J]; JOURNAL OF BEIJING INSTITUTE OF TECHNOLOGY;1996-05

[10] Peng Xiwei Mo Bo Cao Fan (Department of Automatic Control, Beijing Institute of Technology, Beijing100081); Electrohydraulic Proportional High Accuracy Point to Point Control Based on 
Variable Deadzone Dynamic Compensation[J]; JOURNAL OF BEIJING INSTITUTE OF TECHNOLOGY;1999-01 